\title{
LEVANTAMENTO FITOSSOCIOLÓGICO DE PLANTAS DANINHAS NA CULTURA DO FEIJÃO-CAUPI NO AGRESTE ALAGOANO
}

\section{Larissa Silva de Oliveira ${ }^{1}$, Reinaldo Silva Oliveira Canuto ${ }^{2}$, Débora Maria Ferreira} Oliveira Canuto ${ }^{3}$

\section{${ }^{1}$ Graduanda do Departamento de Engenharia Agronômica do Instituto Federal do Triângulo Mineiro Campus Uberlândia \\ ${ }^{2}$ Professor Doutor do Departamento de Engenharia Agronômica do Instituto Federal do Triângulo Mineiro Campus Uberlândia, Uberlândia, Brasil (reinaldo@iftm.edu.br) \\ ${ }^{3}$ Doutoranda do Departamento de Entomologia da Universidade de São \\ Paulo/Escola Superior de Agricultura "Luiz de Queiroz"}

Recebido em: 08/04/2017 - Aprovado em: 10/06/2017 - Publicado em: 20/06/2017 DOI: 10.18677/EnciBio 2017A69

\section{RESUMO}

O cultivo de feijão-caupi no Agreste Alagoano consiste em uma atividade importante para o abastecimento do mercado consumidor de Alagoas e estados vizinhos. No entanto, as plantas daninhas constituem um fator biótico prejudicial ao desenvolvimento da cultura por competir por água, nutrientes e luz. Com o objetivo de avaliar a comunidade infestante em feijão-caupi cultivado em sucessão ao amendoim, foi realizado um levantamento fitossociológico e a mensuração da fitomassa verde e seca de cada espécie de planta daninha. O experimento foi conduzido no Sítio Pai João, no município de Taquarana, na região Agreste do Estado de Alagoas. As espécies de plantas daninhas foram identificadas e quantificadas pelo método do quadrado inventário $(0,5 \times 0,5 \mathrm{~m})$, com 50 amostragens realizadas em 100 ha de cultivo de feijão-caupi, aos 30 dias após a semeadura. Foram determinados a frequência, a densidade, a abundância, a frequência relativa, a densidade relativa, a abundância relativa e o índice de valor de importância. Além desses parâmetros, foram avaliadas a massa verde e a massa seca das plantas daninhas. A comunidade infestante na área cultivada com feijãocaupi foi composta por 27 espécies de plantas daninhas, pertencentes a 14 famílias botânicas, havendo predominância de plantas das famílias Poaceae e Asteraceae. As espécies mais abundantes foram, Emilia fosbergii, Amaranthus hybridus, Commelina benghalensis e Eleusine indica, sendo esta última a espécie que apresentou o maior índice de valor de importância.

PALAVRAS-CHAVE: competição, fitossociologia, Vigna unguiculata (L.) Walp.

\section{PHYTOSOCIOLOGICAL SURVEY OF WEEDS IN COWPEA-BEAN CROP IN AGRESTE ALAGOANO, STATE OF ALAGOAS, BRAZIL}

\footnotetext{
ABSTRACT

The cowpea production in Agreste region in the Alagoas Province is an activity of great importance in supplying the consumer market of Alagoas and neighboring states. However, the weeds are a biotic factor detrimental to the development of the crop because it competes for water, nutrients and light. In order to evaluate the weed ENCICLOPÉDIA BIOSFERA, Centro Científico Conhecer - Goiânia, v.14 n.25; p.861 2017
} 
community in cowpea cultivated in succession to the peanut, a phytosociological survey and a measurement of green and dry phytomass of each weed species were carried out. The experiment was conducted at Sítio Pai João, in the municipality of Taquarana, in the Agreste region of the State of Alagoas. Damaged plant species were identified and quantified using the inventory square method $(0.5 \times 0.5 \mathrm{~m})$, with 50 samples taken in 100 ha of cowpea, 30 days after sowing. The frequency, density, abundance, relative frequency, relative density, relative abundance and importance value index were evaluated. In addition to the parameters, the green mass and the dry mass of the weeds were evaluated. The weed community in the area with cowpea was composed of 27 weed species, belonging to 14 botanical families, with predominance of Poaceae and Asteraceae. The most abundant species were Emilia fosbergii, Amaranthus hybrudus, Commelina benghalensis and Eleusine indica, being the latter species that presented the highest importance value index.

KEYWORDS: competition, phytosociology, Vigna unguiculata (L.) Walp

\section{INTRODUÇÃO}

O feijão-caupi (Vigna unguiculata) é um alimento rico em proteínas e de baixo custo que desempenha um importante papel socioeconômico nas regiões norte e nordeste do país onde é amplamente cultivado (CORRÊA et al., 2015). É uma cultura adaptada a temperaturas elevadas, que apresenta certa rusticidade por se desenvolver em solos pouco férteis e com baixa disponibilidade hídrica (FREITAS et al., 2009).

Para que uma cultura expresse seu potencial produtivo é necessário realizar o controle adequado de pragas, doenças e principalmente de plantas daninhas que é um dos principais problemas associados a produção de feijão-caupi. Uma vez não controladas, as plantas daninhas competem pelos recursos essenciais ao desenvolvimento da cultura como água, luz e nutrientes. Essa competição pode ocasionar perdas de até $90 \%$ no rendimento de grãos e consequentemente reduzir a produção e o lucro (MANCUSO et al., 2016).

Um dos principais métodos de controle de plantas daninhas em uma cultura é a utilização do controle químico com herbicidas (MANABE et al., 2014), pois permite alta eficácia de controle e redução de custos na produção (MANCUSO et al., 2016). Porém, para o feijão-caupi, ainda há escassez de informações sobre a seletividade dos herbicidas à cultura, sendo ainda muito comum a utilização de controle com capinas, com baixo rendimento operacional, além do controle cultural (OLIVEIRA et al., 2013; FONTES et al., 2013).

Para adotar uma medida de controle no manejo de plantas daninhas é imprescindível o conhecimento das plantas presentes na cultura, sendo necessário um diagnóstico prévio e quantificação dessas populações de plantas. Através da utilização da fitossociologia é possível identificar quais são essas populações, assim como a frequência, abundância e densidade das plantas daninhas presentes em determinado cultivo (MARQUES et al., 2010). Sendo assim, este trabalho apresentou como objetivo a realização do levantamento fitossociológico de plantas daninhas na cultura do feijão-caupi.

\section{MATERIAL E MÉTODOS}

O experimento foi realizado em área de produção de feijão-caupi no município de Taquarana ( $9^{\circ} 38^{\prime} 56^{\prime \prime}$ de latitude Sul e $36^{\circ} 29^{\prime} 49^{\prime \prime}$ de longitude Oeste), no estado de Alagoas. A semeadura foi realizada, mecanicamente, no dia 11 de 
março de 2013, em sucessão ao cultivo de amendoim, com 10 plantas por metro linear e espaçamento entre linhas de $0,5 \mathrm{~m}$ em uma área de 100 hectares. A adubação foi realizada durante a semeadura com o adubo formulado NPK (20-2820). A produção de feijão-caupi foi realizada visando a colheita de vagens para abastecer o mercado consumidor de grãos verdes, cujo consumo é muito comum na região Nordeste do Brasil. As vagens são distribuídas em distribuídas em cinco Centrais Estaduais de Abastecimento (CEASA's) localizadas em Alagoas, Recife, Pernambuco e Sergipe.

O levantamento das plantas daninhas foi realizado aos 30 dias após a semeadura do feijão-caupi. As plantas daninhas foram identificadas e quantificadas pelo método do quadrado inventário (BRAUN-BLANQUET, 1979) em toda a área cultivada. Foi utilizado um quadrado de $0,5 \mathrm{~m} \times 0,5 \mathrm{~m}$ para demarcar aleatoriamente 50 áreas amostradas no interior do setor de produção, numa área total de 100 ha. Após a contagem do número de plantas de cada espécie, cada planta foi cortada rente ao solo e acondicionada em sacos plásticos e colocadas em caixas térmicas para evitar a perda de umidade. No Laboratório de Fitossanidade da Universidade Federal de Alagoas, Campus Arapiraca, as plantas foram pesadas para aferição da massa verde e, em seguida, foram colocadas em estufa com ventilação forçada regulada à $60^{\circ} \mathrm{C}$ por 72 horas. Decorrido esse período, foi realizada a avaliação da massa seca.

A partir da contagem do número de indivíduos de cada espécie de planta daninha, os seguintes parâmetros fitossociológicos propostos por MÜELLERDOMBOIS \& ELLENBERG (1974) foram calculados: Frequência = (número de quadrados onde a espécie foi encontrada/número total de quadrados; Densidade) = (número total de indivíduos da espécie / número total de quadrados); Abundância = (número total de indivíduos da espécie / número total de quadrados onde a espécie foi encontrada); Frequência relativa $=(($ frequência da espécie $\times 100) /$ frequência total das espécies); Densidade relativa $=(($ densidade da espécie $\times 100) /$ densidade total das espécies); Abundância relativa $=$ ((abundância da espécie $x$ 100) / abundância total das espécies); e Índice de Valor de Importância = (frequência relativa + densidade relativa + abundância relativa). Os resultados foram apresentados de forma descritiva em tabelas.

\section{RESULTADOS E DISCUSSÃO}

Com a identificação e quantificação das espécies de plantas daninhas na área total de feijoeiro foi possível determinar a comunidade infestante no local (Quadro 1). A comunidade infestante na área cultivada com feijão-caupi foi composta por 27 espécies de plantas daninhas, pertencentes a 14 famílias botânicas, havendo predominância de plantas das famílias Poaceae e Asteraceae. Entre as famílias identificadas, a Poaceae foi a que obteve maior riqueza, perfazendo um total de sete espécies pertencentes à família, cerca de $26 \%$ do total das espécies de plantas amostradas na área de estudo. A família Asteraceae também obteve um número expressivo de espécies, cerca de $19 \%$ da riqueza total.

As famílias com maior número de espécies encontradas no presente estudo (Poaceae e Asteraceae) estão entre as principais famílias de plantas daninhas existentes no Brasil (OLIVEIRA \& FREITAS, 2008). Várias espécies pertencentes à família Poaceae são perenes e produzem um número elevado de sementes aumentando seu poder de disseminação e colonização de diferentes ambientes (CARDOSO et al., 2013). 
QUADRO 1 Relação de plantas daninhas, distribuídas por família e espécie, presentes em feijoeiros cultivados no município de Taquarana, Alagoas.

\begin{tabular}{|c|c|c|}
\hline Família & Nome Popular & Nome Científico \\
\hline Amaranthaceae & $\begin{array}{l}\text { Bredo } \\
\text { Bredo-rasteiro }\end{array}$ & $\begin{array}{l}\text { Amaranthus hybridus var. patulus } \\
\text { Amaranthus deflexus }\end{array}$ \\
\hline Asteraceae & $\begin{array}{l}\text { Mentrasto } \\
\text { Falsa-serralha } \\
\text { Buva } \\
\text { Carrapicho-de-carneiro } \\
\text { Picão-branco }\end{array}$ & $\begin{array}{l}\text { Ageratum conyzoides } \\
\text { Emilia fosbergii } \\
\text { Conyza canadensis } \\
\text { Acanthospermum hispidum } \\
\text { Galinsoga parviflora }\end{array}$ \\
\hline Boraginaceae & Crista-de-galo & Heliotropium indicum \\
\hline Commelinaceae & Rabo-de-cachorro & Commelina benghalensis \\
\hline Convolvulaceae & Corda-de-viola & Ipomoea triloba \\
\hline Cyperaceae & Junça & Cyperus iria \\
\hline Euphorbiaceae & Burra-leiteira & Chamaesyce hirta \\
\hline Fabaceae & Malícia & Mimosa pudica \\
\hline Malvaceae & Malva-preta & Sidastrum micranthum \\
\hline Moluginaceae & Capim-tapete & Mollugo verticillata \\
\hline Phyllanthaceae & Quebra-pedra & Phyllanthus tenellus \\
\hline \multirow{5}{*}{ Poaceae } & $\begin{array}{l}\text { Capim-pé-de-galinha } \\
\text { Capim-mão-de-sapo } \\
\text { Capim-colchão }\end{array}$ & $\begin{array}{l}\text { Eleusine indica } \\
\text { Dactyloctenium aegyptium } \\
\text { Digitaria sanguinalis }\end{array}$ \\
\hline & Capim-marmelada & Brachiaria plantaginea \\
\hline & Capim-oferecido & Pennisetum setosum \\
\hline & Capim-gengibre & Paspalum maritimum \\
\hline & Capim-amargoso & Digitaria insularis \\
\hline Rubiaceae & $\begin{array}{l}\text { Vassourinha-de-botão } \\
\text { Poaia-branca }\end{array}$ & Borreria densiflora \\
\hline Solanaceae & Maria-pretinha & Solanum americanum \\
\hline
\end{tabular}

$\mathrm{Na}$ área amostrada de feijão-caupi, as espécies encontradas em maior densidade e frequência foram: capim-pé-de-galinha (Eleusine indica) com densidade de 24 plantas $\mathrm{m}^{-2}$ e 18,08\% de frequência, falsa serralha (Emilia fosbergii) com densidade de 14,72 plantas $\mathrm{m}^{-2}$ e $6,78 \%$ de frequência, bredo (Amaranthus hybridus) com densidade de 10,88 plantas $\mathrm{m}^{-2}$ e $8,78 \%$ de frequência e o rabo de cachorro (Commelina benghalensis) com densidade de 10,61 plantas $\mathrm{m}^{-2}$ e $10,73 \%$ de frequência (Tabela 1). As reduções de produtividade resultantes da competição das plantas daninhas com a cultura dependem da densidade de plantas e da distribuição delas no campo (MOURA FILHO et al., 2015), de tal forma que em densidades elevadas, as plantas daninhas intensificam a disputa pelos recursos essenciais ao desenvolvimento da cultura (CORRÊA et al., 2015). 
TABELA 1 Número de presença em quadrados (NQ), número de indivíduos (NI), frequência (F), densidade (D), abundância (A), frequência relativa (Fr), densidade relativa (Dr), abundância relativa (Ar) e Índice de Valor de Importância (IVI) das espécies de plantas daninhas presentes no cultivo de feijão-caupi, no Agreste Alagoano.

\begin{tabular}{|c|c|c|c|c|c|c|c|c|c|}
\hline Espécie & $\mathrm{NI}$ & NQ & $\mathrm{F}$ & $\mathrm{D}$ & A & $\mathrm{Fr}$ & Dr & $\mathrm{Ar}$ & IVI \\
\hline Eleusine indica & 75 & 32 & 64 & 24 & 2,34 & 18,08 & 24,12 & 6,41 & 83,17 \\
\hline Emilia fosbergii & 46 & 12 & 24 & 14,72 & 3,83 & 6,78 & 14,79 & 10,49 & 26,83 \\
\hline Amaranthus hybridus var. patulus & 34 & 15 & 30 & 10,88 & 2,27 & 8,47 & 10,93 & 6,20 & 26,70 \\
\hline Commelina benghalensis & 33 & 19 & 38 & 10,56 & 1,74 & 10,73 & 10,61 & 4,75 & 35,44 \\
\hline Mollugo verticillata & 18 & 14 & 28 & 5,76 & 1,29 & 7,91 & 5,79 & 3,52 & 15,67 \\
\hline Dactyloctenium aegyptium & 14 & 7 & 14 & 4,48 & 2,00 & 3,95 & 4,50 & 5,47 & 11,75 \\
\hline Ageratum conyzoides & 14 & 13 & 26 & 4,48 & 1,08 & 7,34 & 4,50 & 2,95 & 17,36 \\
\hline Chamaesyce hirta & 12 & 8 & 16 & 3,84 & 1,50 & 4,52 & 3,86 & 4,11 & 10,82 \\
\hline Ipomoea triloba & 11 & 9 & 18 & 3,52 & 1,22 & 5,08 & 3,54 & 3,34 & 8,87 \\
\hline Richardia brasiliensis & 11 & 8 & 16 & 3,52 & 1,38 & 4,52 & 3,54 & 3,76 & 10,75 \\
\hline Heliotropium indicum & 7 & 5 & 10 & 2,24 & 1,40 & 2,82 & 2,25 & 3,83 & 6,03 \\
\hline Phyllanthus tenellus & 6 & 6 & 12 & 1,92 & 1,00 & 3,39 & 1,93 & 2,74 & 6,44 \\
\hline Digitaria sanguinalis & 4 & 4 & 8 & 1,28 & 1,00 & 2,26 & 1,29 & 2,74 & 7,88 \\
\hline Sidastrum micranthum & 4 & 4 & 8 & 1,28 & 1,00 & 2,26 & 1,29 & 2,74 & 4,07 \\
\hline Borreria densiflora & 3 & 2 & 4 & 0,96 & 1,50 & 1,13 & 0,96 & 4,11 & 2,53 \\
\hline Mimosa pudica & 3 & 3 & 6 & 0,96 & 1,00 & 1,69 & 0,96 & 2,74 & 4,54 \\
\hline Acanthospermum hispidum & 2 & 2 & 4 & 0,64 & 1,00 & 1,13 & 0,64 & 2,74 & 3,19 \\
\hline Amaranthus deflexus & 2 & 2 & 4 & 0,64 & 1,00 & 1,13 & 0,64 & 2,74 & 2,19 \\
\hline Digitaria insularis & 2 & 2 & 4 & 0,64 & 1,00 & 1,13 & 0,64 & 2,74 & 1,94 \\
\hline Pennisetum setosum & 2 & 2 & 4 & 0,64 & 1,00 & 1,13 & 0,64 & 2,74 & 4,65 \\
\hline Brachiaria plantaginea & 1 & 1 & 2 & 0,32 & 1,00 & 0,56 & 0,32 & 2,74 & 1,00 \\
\hline Conyza canadensis & 1 & 1 & 2 & 0,32 & 1,00 & 0,56 & 0,32 & 2,74 & 1,36 \\
\hline Cyperus iria & 1 & 1 & 2 & 0,32 & 1,00 & 0,56 & 0,32 & 2,74 & 1,96 \\
\hline Galinsoga parviflora & 1 & 1 & 2 & 0,32 & 1,00 & 0,56 & 0,32 & 2,74 & 1,17 \\
\hline Paspalum maritimum & 1 & 1 & 2 & 0,32 & 1,00 & 0,56 & 0,32 & 2,74 & 0,97 \\
\hline Solanum americanum & 1 & 1 & 2 & 0,32 & 1,00 & 0,56 & 0,32 & 2,74 & 0,96 \\
\hline Não Identificada & 2 & 2 & 4 & 0,64 & 1,00 & 1,13 & 0,64 & 2,74 & 3,41 \\
\hline Total & 311 & - & 354 & 99,52 & 36,54 & 100 & 100 & 100 & 300 \\
\hline
\end{tabular}


Em relação a abundância das espécies, as espécies Eleusine indica, Emilia fosbergii, Amaranthus hybridus e Commelina benghalensis foram as que apresentaram maior número de indivíduos por espécie. A planta daninha mais abundante foi a Eleusine indica, que teve o maior número de indivíduos da espécie em relação as outras espécies amostradas. O capim-pé-de galinha apresenta alta capacidade competitiva com as plantas cultivadas, possui alta taxa de fecundação e capacidade de se adaptar a diversos ambientes. O controle dessa espécie está se tornando cada vez mais difícil devido ao desenvolvimento de resistência da planta aos herbicidas utilizados em seu controle (BRUNHARO et al., 2014).

Quanto ao índice de valor de importância (IVI) as espécies que apresentaram domínio na área de feijão-caupi foram: Eleusine indica, Emilia fosbergii, Amaranthus hybridus e Commelina benghalensis. Juntamente com o Ageratum conyzoides, essas espécies apresentaram os maiores valores de matéria fresca e matéria verde (Tabela 2), indicando que tais plantas daninhas devem ser consideradas como alvos principais de controle.

TABELA 2 Matéria fresca e matéria verde das espécies de plantas daninhas presentes no cultivo de feijão-caupi, no Agreste Alagoano.

\begin{tabular}{lcc}
\hline Espécie & Matéria fresca $(\mathrm{g})$ & Matéria seca $(\mathrm{g})$ \\
\hline Eleusine indica & 653,49 & 227,00 \\
Commelina benghalensis & 237,18 & 74,00 \\
Emilia fosbergii & 111,51 & 29,16 \\
Ageratum conyzoides & 91,04 & 30,53 \\
Amaranthus hybridus var. patulus & 91,00 & 44,03 \\
Richardia brasiliensis & 89,74 & 14,91 \\
Digitaria sanguinalis & 81,11 & 24,01 \\
Dactyloctenium aegyptium & 70,93 & 18,24 \\
Chamaesyce hirta & 60,42 & 13,53 \\
Mollugo verticillata & 52,90 & 10,92 \\
Acanthospermum hispidum & 44,29 & 7,83 \\
Pennisetum setosum & 40,00 & 15,92 \\
Mimosa pudica & 38,92 & 10,40 \\
Heliotropium indicum & 33,59 & 5,30 \\
Phyllanthus tenellus & 25,14 & 6,37 \\
Cyperus iria & 18,38 & 5,94 \\
Galinsoga parviflora & 13,64 & 1,55 \\
Conyza canadensis & 12,68 & 2,62 \\
Sidastrum micranthun & 12,53 & 2,92 \\
Amaranthus deflexus & 9,84 & 2,29 \\
Borreria densiflora & 8,22 & 2,43 \\
Ipomoea triloba & 6,92 & 1,42 \\
Digitaria insularis & 6,88 & 0,93 \\
Brachiaria plantaginea & 6,10 & 1,20 \\
Paspalum maritimum & 4,10 & 0,48 \\
Solanum americanum & 1,59 & 0,39 \\
\hline
\end{tabular}


O conhecimento prévio de quais espécies de plantas daninhas existem em um determinado local, bem como a população e distribuição na área, permite que haja um planejamento mais pontual com medidas de controle mais adequadas (CARDOSO, et al., 2013). Assim, é possível evitar o desvio de água e nutrientes que deveriam ser melhor aproveitados pela cultura do feijão-caupi.

\section{CONCLUSÃO}

$\mathrm{Na}$ área de feijão-caupi no município de Taquarana-AL encontrou-se um maior número de espécies de plantas daninhas das famílias Asteraceae e Poaceae. As espécies mais abundantes foram, Emilia fosbergii, Amaranthus hybridus, Commelina benghalensis e Eleusine indica, sendo esta última a espécie que apresentou o maior índice de valor de importância.

\section{REFERÊNCIAS}

BRAUN-BLANQUET, J. Fitossociologia: bases para el estudio de las comunidades vegetales. Madrid: H. Blume, 1979. 820 p.

BRUNHARO, C. A. C. G.; CHRISTOFFOLETI, P. J.; NICOLAI, M. Aspectos do mecanismo de ação do amônio glufosinato: culturas resistentes e resistência de plantas daninhas. Revista Brasileira de Herbicidas, v. 13, n. 2, p. 163-177, 2014. Disponível em: <http://dx.doi.org/10.7824/rbh.v13i2.293>. doi: 10.7824/rbh.v13i2.293.

CARDOSO, A. D.; VIANA, A. E. S; BARBOSA, R. P.; TEIXEIRA, P. R. G.; CARDOSO JÚNIOR, N. S.; FOGAÇA, J. J. N. L. Levantamento fitossociológico de plantas daninhas na cultura da mandioca em Vitória da Conquista, Bahia. Bioscience Journal, v. 29, n. 5, p. 1130-1140, 2013. Disponível em: <http:// http://www.seer.ufu.br/index.php/biosciencejournal/article/view/22127/13007>.

Acesso em 02 de abril de 2017.

CORRÊA, M. J. P.; ALVES, G. L.; ROCHA, L. G. F.; SILVA, M. R. M. Períodos de interferência de plantas daninhas na cultura do feijão caupi. Revista de Ciências Agroambientais, v. 13, n. 2, p. 50-56, 2015. Disponível em: <http:// http://periodicos.unemat.br/index.php/rcaa/article/view/1183/1257>. Acesso em 02 de abril de 2017.

FREITAS, F. C. L.; MEDEIROS, V. F. L. P.; GRANGEIRO, L. C.; SILVA, M. G. O.; NASCIMENTO, P. G. M. L.; NUNES, G. H. Interferência de plantas daninhas na cultura do feijão-caupi. Planta Daninha, v. 27, n. 2, p. 241-247, 2009. Disponível em: <http://www.scielo.br/pdf/pd/v27n2/05.pdf>. Acesso em 02 de abril de 2017.

FONTES, J. R. A.; OLIVEIRA, I. J.; GONÇALVES, J. R. P. Seletividade e eficácia de herbicidas para cultura do feijão-caupi. Revista Brasileira de Herbicidas, v. 12, n. 1, p. 47-55, 2013. Disponível em: <http://dx.doi.org/10.7824/rbh.v12i1.214>. doi: 10.7824/rbh.v12i1.214.

MANABE, P. M. S.; MATOS, C. C.; FERREIRA, E. A.; SILVA, A. A.; SEDIYAMA, T.; MANABÉ, A.; SILVA, A. F.; ROCHA, P. R. R.; GALON, L. Características fisiológicas de feijoeiro em competição com plantas daninhas. Bioscience Journal, v. 30, n. 6 , 
2014.

Disponível

em:

<http://www.seer.ufu.br/index.php/biosciencejournal/article/view/22147/15609>.

Acesso em 02 de abril de 2017.

MANCUSO, M. A. C.; AIRES, B. C.; NEGRISOLI, E.; CORRÊA, M. R.; SORATTO, R. P. Seletividade e eficiência de herbicidas no controle de plantas daninhas na cultura do feijão-caupi. Ceres, v. 63, n. 1, 2016. Disponível em: < http://dx.doi.org/10.1590/0034-737X201663010004>. doi: 10.1590/0034737X201663010004.

MARQUES, L. J. P.; SILVA, M. R. M.; ARAÚJO, M. S.; LOPES, G. S.; CORRÊA, M. J. P.; FREITAS, A. C. R.; MUNIZ, F. H. Composição florística de plantas daninhas na cultura do feijão-caupi no sistema de capoeira triturada. Planta Daninha, v. 28, p. 953-961, 2010. Disponível em: <http://dx.doi.org/10.1590/S0100$83582010000500003>$. doi: 10.1590/S0100-83582010000500003.

MOURA FILHO, E. R.; MACEDO, L. P. M.; SILVA, A. R. S. Levantamento fitossociológico de plantas daninhas em cultivo de banana irrigada. Holos, v. 2, p. 92-97, 2015. Disponível em: < http://dx.doi.org/10.15628/holos.2015.1006>. doi: 10.15628/holos.2015.1006.

MUELLER-DOMBOIS, D.; ELLENBERG, H. Aims and methods of vegetation ecology. New York: Wiley and Sons, 1974. 547 p.

OLIVEIRA, A. R.; FREITAS, S. P. Levantamento fitossociológico de plantas daninhas em áreas de produção de cana-de-açúcar. Planta Daninha, v. 26, n. 1, p. 33-46, 2008. Disponível em: <http://dx.doi.org/10.1590/S010083582008000100004>. doi: 10.1590/S0100-83582008000100004.

OLIVEIRA, M. B.; ALVES, P. F. S.; TEIXEIRA, M. F. F.; SILVA, H. D.; SÁ, R. A.; CAMPOS, R. G. C.; CARVALHO, A. J.; ASPIAZÚ, I. Fitotoxicidade de herbicidas aplicados em diferentes épocas em pós-emergência do feijão-caupi. Revista Unimontes Científica, v. 15, n. 1, p. 62-70, 2013. Disponível em: $<$ http://ruc.unimontes.br/index.php/unicientifica/article/view/135>. Acesso em $17 \mathrm{de}$ janeiro de 2017. 